\title{
Weaning strategies to improve the performance of sows and their progeny under smallholder farming conditions
}

\author{
D.R. Kugonza" and D. Mutetikka \\ Department of Animal Science, Faculty of Agriculture, Makerere University, P.O. Box 7062, Kampala, Uganda
}

\begin{abstract}
The effect of restricted suckling and split weaning on the reproductive performance of dams and subsequent performance of their litters was studied in an experiment involving 48 Landrace $\mathrm{x}$ Large White sows of second and third parity. The sows and their litters were allocated to four treatments as follows: separation to allow either one or two 30 minute periods of suckling per day, reduction of litter size by weaning all piglets attaining $6 \mathrm{~kg}$ body weight and a control in which suckling was not restricted. Treatments commenced when piglets attained four weeks of age and were weaned at eight weeks of age. Restricted suckling resulted in an increased creep feed intake by the piglets. Piglets that were suckled once a day consumed $8.76 \mathrm{~kg}$ creep feed during the experimental period compared to 8.49, 8.35 and $8.21 \mathrm{~kg}$ for split weaning, twice a day suckling and the control, respectively. All intakes were significantly different. No differences were observed between treatments in total weight gain over the four week period. Sows in the control treatment had an average wean to oestrus interval (WOI) of 17 days. Restricting piglets to suckling once or twice a day, or split weaning had a positive effect of significantly reducing the WOI compared to the control. A number of sows exhibited oestrus during lactation, with the sows in the twice a day suckling treatment having a larger percentage than those in the other treatments. Restricting suckling and split weaning have an advantage of improving the reproductive performance of the sows without compromising piglet survival or growth. We recommend restricting piglet suckling to twice a day, and weaning of all piglets attaining six kg live weight.
\end{abstract}

Keywords: Sow, pigs, reproduction, suckling, wean, oestrus, small-scale farmer

${ }^{\#}$ Corresponding author. E-mail: donkugonza@agric.mak.ac.ug

\section{Introduction}

Under smallholder production conditions in Uganda early weaning is not a recommended management practice given the high costs of the specialized diet required for early weaned piglets (Nelssen, 1990) coupled with lack of infrastructure to care for them. A long lactation period results in the so-called thin-sow condition at weaning, and consequently requiring in excess of three weeks before returning to oestrus after weaning. In a management system where the recommended lactation length is as long as eight weeks, a reduction in the wean to service interval would increase the number of litters per sow per year and, providing the other determinants of sow efficiency remained unchanged, would improve sow output. Management practices which reduce the intensity of suckling have been known to reduce sow weight loss during lactation (Xue et al., 1993) and wean to first oestrus interval in sows (Mahan, 1993). Dritz et al. (1994) reported that shorter than conventional lactation lengths led to increased reproductive efficiency as a result of increased litters per sow per year. Partial separation of the sow and litter is known to initiate oestrus during lactation (Crighton, 1961; Smith, 1961; Saihlira et al., 1991), or to decrease the interval to remating after weaning (Smith, 1961). Smith (1961) reported that separation, beginning 3-4 weeks post partum, was sufficient to induce oestrus during lactation in sows. Separation of sows from their litters leads to a reduction in milk consumption by the piglets and consequently a substantial reduction in milk production by the sow. Reduced milk production would lead to reduced nutrient depletion of the sows and hence less weight loss. Koketsu (2000) reported that duration of lactation did not affect the number of piglets weaned per year (PWY); the number of piglets weaned per mated female per year (PWMFY), but was not correlated with litters per mated females per year (LMFY). This study aimed at assessing the effect of restricted suckling and split weaning as management practices that reduce suckling intensity and lactational weight loss, on the performance of sows and their litters under smallholder farming conditions in Uganda. 


\section{Materials and Methods}

A total of 48 Landrace $x$ Large White sows of second or third parity from two different farms, the Makerere University Agricultural Research Institute, Kabanyolo and a private farm at Seeta, Mukono district was used. The experiment was conducted from June 2003 to September 2004. A randomized complete design consisting of four treatments was used. The sows were divided into four groups of 12 animals each, balanced for lactational status. They were randomly allocated to the following management treatments: 1) separation of sows from their litters by allowing one 30 min period of suckling per day,2) separation to allow two 30 min periods of suckling per day, 3) reduction in litter size by weaning every piglet attaining six $\mathrm{kg}$ body weight, beginning four weeks post partum and 4) a control treatment where piglets were left with their mother for the entire eight-week lactation period. The trial commenced when a litter reached four weeks of age.

The sows and litters were fed a concentrate mixture containing sorghum and maize, respectively. A sow was fed a sow and weaner meal $(140 \mathrm{~g} \mathrm{CP} / \mathrm{kg})$ at a daily rate of two $\mathrm{kg}$ and $0.25 \mathrm{~kg}$ additional per suckling piglet. The daily ration was divided into two equal meals, one in the morning and the other in the afternoon. The composition of the experimental diets is provided in Table 1 . The litters were provided free access to a creep feed $(210 \mathrm{~g} \mathrm{CP} / \mathrm{kg})$ in a creep area (Table 1$)$.

Table 1 Composition of experimental diets ( $\mathrm{g} / \mathrm{kg}$ as fed basis)

\begin{tabular}{lrr}
\hline Ingredient & Sow and weaner meal & Creep meal \\
\hline Maize meal & -- & 682 \\
Sorghum meal & 812 & -- \\
Fish meal & 150 & 298 \\
Oyster shells & 30 & 10 \\
Salt & 5 & 5 \\
Vitamin-mineral premix * & 3 & 5 \\
Total & 1000 & 1000
\end{tabular}

* Provided per kg diet: Vitamin A - 12,500 I.U.; vitamin $\mathrm{D}_{3}$ - 2500 I.U.; vitamin E - 20 I.U.; vitamin $\mathrm{K}_{3}$ - 3.0 mg; vitamin $\mathrm{B}_{1}$ - $1.0 \mathrm{mg}$; vitamin $\mathrm{B}_{2}-5.0 \mathrm{mg}$; vitamin $\mathrm{B}_{6}-1.0 \mathrm{mg}$; vitamin $\mathrm{B}_{12}-0.05 \mathrm{mg}$; nicotinic acid - $11.25 \mathrm{mg}$; calcium pantothenate - 6 mg; choline - 0.1 mg; manganese - 75 mg; iron - 37.5 mg; zinc - 62 mg; copper - 6 mg; iodine - 1.0 mg; selenium - 0.12 mg (Source: Frank Wright Ltd., BASF Group, U.K.; distributed by Cooper Uganda Ltd)

During pregnancy, the sows were kept outdoors on pasture in paddocks equipped with water troughs and ample shade. The pasture composed of Panicum maximum, Branchiaria sp., Setaria sp., Cynodon dactylon, Desmodium sp. and Centrosema sp. The sows were group-fed on the $140 \mathrm{~g} \mathrm{CP} / \mathrm{kg}$ sow and weaner meal on open-air concrete pads. They remained together until late gestation, when each was moved to a farrowing pen. The partially open pens had sleeping, exercise and creep areas. The sleeping area fitted with a feed trough and a guardrail, had grass bedding and was roofed. The exercise area had incomplete walls with a water trough. The creep area was connected to the sleeping area through a $30 \mathrm{~cm}$ square window, and was covered with a corrugated asbestos roof. Any sow exhibiting oestrus during the experiment was mated in an attempt to establish pregnancy during lactation.

Daily creep feed intake and weekly weight of piglets during the trial were measured. Piglet mortality was recorded when it occurred. Sow body condition at onset of trial and at weaning of the litters was scored on a 1-10 scale. This scale was chosen because of the wide variation in body condition of the sows at weaning as compared to the conventional 1-5 scale (Patience \& Thacker, 1989). The interval (in days) from weaning to oestrus (WOI) was recorded. Where sows came on oestrus before weaning, the dates were recorded, as was the litter size at subsequent farrowing. Data were subjected to Analysis of Variance using Statistical Analysis Systems (SAS, 2001) and the General Linear Model's procedure. Means were compared, using Least Significant Difference. 


\section{Results and Discussion}

Suckling regimen of piglets affected $(\mathrm{P}<0.05)$ their creep feed intake (Table 2) and live weight at all pre-weaning ages (Table 3). Feed intake increased with age and averaged 1.0, 1.8, 2.5 and $3.3 \mathrm{~kg}$ for weeks 5, 6, 7 and 8, respectively. Piglets that were suckled once a day had the highest total creep intake (8.76 kg), higher $(\mathrm{P}<0.05)$ than those suckling twice a day $(8.35 \mathrm{~kg})$ and than those on the ad libitum $(8.21 \mathrm{~kg})$ and split weaning $(8.49 \mathrm{~kg})$ treatments. This could have been due to the shortfall in nutrient intake because of the reduction in amount of milk obtained from the dam. The similarity of body weight at weaning of the restricted piglets compared to control litters supports the report of Grinwich \& McKay (1985) that body weight two weeks after weaning of piglets subjected to suckling restriction is equal to that of piglets not restricted but weaned after five weeks. Weight gain of the piglets over the four-week trial period was 2.48, 3.45 and $3.32 \mathrm{~kg}$ when suckled once, twice a day and ad libitum (control), respectively. Piglets that were restricted in suckling compensated by consuming more creep. This enabled them to attain growth consonant with piglets on the unrestricted suckling regimen. Piglets that were split weaned gained $2.73 \mathrm{~kg}$, and did not differ $(\mathrm{P}>0.05)$ from the other treatments, probably because of compensatory creep intake.

Table 2 Mean creep feed intake (kg) of piglets under different suckling regimens

\begin{tabular}{|c|c|c|c|c|c|}
\hline \multirow{3}{*}{ Treatment } & \multicolumn{4}{|c|}{ Feed intake (kg) per week } & \multirow{3}{*}{$\begin{array}{c}\text { Total } \\
\text { (kg) }\end{array}$} \\
\hline & \multicolumn{4}{|c|}{ Week } & \\
\hline & 5 & 6 & 7 & 8 & \\
\hline Suckling once a day & $1.06^{\mathrm{a}}$ & $1.73^{\mathrm{a}}$ & $2.53^{a}$ & $3.44^{\mathrm{a}}$ & $8.76^{\mathrm{a}}$ \\
\hline Suckling twice a day & $1.01^{\mathrm{b}}$ & $1.71^{\mathrm{a}}$ & $2.34^{\mathrm{b}}$ & $3.29^{b}$ & $8.35^{b}$ \\
\hline Split weaning $*$ & $0.89^{c}$ & $1.79^{b}$ & $2.60^{\mathrm{a}}$ & $3.20^{\mathrm{c}}$ & $8.49^{\mathrm{C}}$ \\
\hline Control ** & $0.84^{\mathrm{d}}$ & $1.77^{\mathrm{b}}$ & $2.42^{b}$ & $3.18^{\mathrm{d}}$ & $8.21^{\mathrm{d}}$ \\
\hline $\mathrm{LSD}_{0.05}$ & 0.02 & 0.03 & 0.09 & 0.01 & 0.09 \\
\hline
\end{tabular}

a, b, c, d Column means with different superscripts differ significantly $(\mathrm{P}<0.05)$

* Weaned when individual piglet attained a body weight of six kg

** Suckling not restricted

Table 3 Mean piglet body weights and mortality under different suckling regimens

\begin{tabular}{|c|c|c|c|c|c|c|}
\hline \multirow{3}{*}{ Treatment } & \multicolumn{4}{|c|}{ Body weight (kg) } & \multirow{3}{*}{$\begin{array}{l}\text { Total gain } \\
\quad(\mathrm{kg})\end{array}$} & \multirow{3}{*}{$\begin{array}{c}\text { Piglet mortality } \\
\text { from weeks } 4 \text { to } 8 \\
(\%)\end{array}$} \\
\hline & \multicolumn{4}{|c|}{ Week } & & \\
\hline & 5 & 6 & 7 & 8 & & \\
\hline Suckling once a day & $6.09^{a}$ & $6.68^{\mathrm{a}}$ & $7.74^{\mathrm{a}}$ & $8.19^{\mathrm{a}}$ & $2.48^{\mathrm{a}}$ & $0.3^{\mathrm{a}}$ \\
\hline Suckling twice a day & $6.40^{\mathrm{a}}$ & $7.82^{\mathrm{b}}$ & $8.61^{b}$ & $9.22^{b}$ & $3.45^{b}$ & $0^{\mathrm{b}}$ \\
\hline Split weaning $*$ & $5.52^{b}$ & $5.56^{\mathrm{c}}$ & $6.17^{c}$ & $6.42^{c}$ & $2.73^{\mathrm{ab}}$ & $0^{\mathrm{b}}$ \\
\hline Control ** & $6.24^{\mathrm{a}}$ & $6.90^{\mathrm{a}}$ & $7.75^{\mathrm{a}}$ & $9.30^{\mathrm{b}}$ & $3.32^{\mathrm{ab}}$ & $0^{\mathrm{b}}$ \\
\hline $\mathrm{LSD}_{0.05}$ & 0.405 & 0.381 & 0.740 & 0.895 & 0.895 & 0.08 \\
\hline
\end{tabular}

Our results confirmed other reports where reduced litter size resulted in either earlier post weaning returns to oestrus or an increased proportion of sows in oestrus at various post weaning intervals (Britt \& Levis, 1980; Stevenson \& Britt, 1981; Cox et al., 1983). Weekly live weights of piglets decreased $(\mathrm{P}<0.001)$ with increasing litter size. The average weight per piglet at four weeks of age was $9.42 \pm 0.63 \mathrm{~kg}$ (litter size 3) and $5.63 \pm 0.26 \mathrm{~kg}$ (litter size 8), while the respective weights at eight weeks of age were 10.26 
$\pm 1.3 \mathrm{~kg}$ (litter size 3 ) and $6.73 \pm 0.69 \mathrm{~kg}$ (litter size 8$)$. Weaning to oestrus interval increased $(\mathrm{P}<0.001)$ with increase in litter size. Small litter size had the same effect as split weaning, showing that split weaning reduces the WOI of sows that lactate beyond four weeks (Matte et al., 1992). Large litter sizes are associated with poor sow condition at weaning. The number of nursing piglets influences the number of days for a sow to return to oestrus due to the increased lactation demands on the sow associated with large litters and the hormonal feedback mechanism of lactation suppressing reproductive hormones (Matte et al., 1992).

Table 4 shows the weaning to oestrus interval, body condition score at weaning and subsequent litter sizes of the sows in the respective treatments. Sows whose litters were restricted to suckling twice a day came on oestrus before weaning (Table 4), while those in the unrestricted suckling treatment came on oestrus after a fortnight. Findings of this study corroborate with those of Mabry et al. (1996) who found that lactation length exerted a significant quadratic effect on weaning to first service interval (WSI). They reported that WSI was significantly increased when length of lactation was more than 27 days. Body condition of the sows varied $(\mathrm{P}<0.05)$ across all treatments with the highest score being recorded for the split weaning group. Sows that suckled their litters once a day had the highest subsequent litter sizes while split weaning resulted in the lowest litter sizes (Table 4).

Table 4 Mean intervals from weaning to oestrus, body condition scores of sows and subsequent litter sizes under different suckling regimens

\begin{tabular}{lccc}
\hline Treatment & $\begin{array}{c}\text { Days from } \\
\text { weaning to } \\
\text { oestrus }\end{array}$ & $\begin{array}{c}\text { Body condition } \\
\text { score } \text { of sow at }^{\text {weaning }}\end{array}$ & $\begin{array}{c}\text { Litter size (n) at } \\
\text { subsequent } \\
\text { farrowing }\end{array}$ \\
\hline Suckling once a day & $3.2^{\mathrm{a}}$ & $7.1^{\mathrm{a}}$ & $11.8^{\mathrm{a}}$ \\
Suckling twice a day & $-2.8^{\mathrm{b}}$ & $6.4^{\mathrm{b}}$ & $8.0^{\mathrm{b}}$ \\
Split weaning * & $1.2^{\mathrm{a}}$ & $8.8^{\mathrm{c}}$ & $7.9^{\mathrm{c}}$ \\
Control ** & $17.0^{\mathrm{c}}$ & $3.7^{\mathrm{d}}$ & $9.5^{\mathrm{d}}$ \\
LSD & 0.46 & 0.10 \\
a, b, c, d Column means with different superscripts differ significantly $(\mathrm{P}<0.05)$ \\
\# On a scale of 1-10; n - number of piglets \\
* Weaned when individual piglet attained a body weight of six kg \\
** Suckling not restricted
\end{tabular}

\section{Conclusions}

Restricting piglet suckling intensity and duration positively affected creep feed intake, implying that intake of feed was inversely proportional to quantity of milk suckled. When piglets suckled for a short time, they compensated with a higher intake of the creep feed. The treatments did not affect weaning weight gain during the trial period. This implies that the compensatory creep feeding met the shortage of nutrients due to short suckling periods. Restricting suckling and split weaning shortened the weaning to oestrus period in the sows, ensuring a high body condition score for the sows at weaning and did not affect their subsequent litter sizes. Litter size and length of lactation determine how much a sow will lose in terms of nutrients in milk. Sow condition at weaning is attributed to many factors such as parity, age and the current feeding level. We therefore recommend restricting piglet suckling to twice a day and weaning of all piglets attaining six kg of live weight. Further studies are needed to quantify effects of sow feeding level and boar exposure during lactation on WOI and oestrus to service interval.

\section{Acknowledgements}

This publication is an output of a research project funded by Sida/SAREC support to the Faculty of Agriculture, Makerere University, Kampala, Uganda. 


\section{References}

Britt, J.H. \& Levis, D.G., 1980. Effect of altered suckling on rebreeding performance in early weaned sows. Proc. Int. Pig Vet. Soc. Congr. 5, 322.

Cox, N.M., Britt, J.H., Armstrong, W.D. \& Alhusen, H.D., 1983. Effect of feeding fat and altering weaning schedule on rebreeding in primiparous sows. J. Anim. Sci. 56, 21-29.

Crighton, D.B., 1961. Pig nutrition with special reference to early weaning. M.Sc. thesis, University of Edinburgh, UK.

Dritz, S.S., Nelssen, J.L., Goodband, R.D., Tokach, M.D. \& Chengappa, M.M., 1994. Application of segregated early weaning technology in the commercial swine industry. Compen. Educ. Pract. Vet. 16 (5), 677-685.

Grinwich, D.L. \& McKay, R.M., 1985. Effects of reduced suckling on days to estrus, conception during lactation and embryo survival in sows. Theriogenology 23, 449-459.

Koketsu, Y., 2000. Reproductive productivity measurements in Japanese swine breeding herds. J. Vet. Med. Sci. 64, 195-198.

Mabry, J.W., Culbertson, M.C. \& Reeves, D., 1996. Effects of lactation length on weaning-to-first-service interval, first-service farrowing rate and subsequent litter size. Swine Health Prod. 4, 185-188.

Mahan, D.C., 1993. Effect of pig weaning weight, associated nursery feeding programs, and nursing period length on performance responses to 230 pound body weight and subsequent effects on sow rebreeding interval. Swine Research and Industrial Report. Ohio State University, 1993. No.92/2, 66-75.

Matte, J.J., Pomar, C. \& Close, W.H., 1992. The effect of interrupted suckling and split-weaning on reproductive performance of sows: A review. Livest. Prod. Sci. 30, 195-212.

Nelssen, J.L., 1990. Recent advances in high nutrient density starter diet research. Proc. $51^{\text {st }}$ Minnesota Nutr. Conf. pp. 217-230 at www.oznet.ksu.edu/prev/PDFs/AIC_2.3.PDF.

Patience, J.F. \& Thacker, P.A., 1989. Swine Nutrition Guide. Prairie Swine Centre, University of Saskatchewan, Saskatoon. pp. 149-171.

Saihlira-Dutta, J.C. \& Borgohain, B.N., 1991. Restricted suckling on the occurrence of post-partum estrus in pig. Ind. Vet. J. 68 (1), 44-46.

SAS, 2001. SAS/STAT version 8.02. Statistical Analysis System Institute, Inc., Cary, North Carolina, USA.

Smith, D.M., 1961. The effect of daily separation of sows from their litters upon milk yield, creep intake, and energetic efficiency. N. Z. J. Agric. Res. 4, 232-245.

Stevenson, J.S. \& Britt, J.H., 1981. Interval to estrus in sows and performance of pigs after alteration of litter size during late lactation. J. Anim. Sci. 53, 177-181.

Xue, J.L., Dial, G.D., Marsh, W.E., Davies, R.P. \& Mormont, H.W., 1993. Influence of lactational length on sow productivity. Livest. Prod. Sci. 33, 253-265. 